\title{
Projections to early visual areas V1 and V2 in the calcarine fissure from parietal association areas in the macaque
}

\author{
Elena Borra ${ }^{1,2 *}$ and Kathleen S. Rockland ${ }^{2,3}$ \\ ' Dipartimento di Neuroscienze, Sezione di Fisiologia, Università di Parma, Istituto Italiano di Tecnologia, (IIT; Unità di Parma), Parma, Italy \\ ${ }^{2}$ Laboratory for Cortical Organization and Systematics, RIKEN Brain Science Institute, Hirosawa, Wako, Japan \\ ${ }^{3}$ RIKEN-MIT Center for Neural Circuit Genetics, Picower Institute for Learning and Memory, MIT, Cambridge, MA, USA
}

\section{Edited by:}

Patrick R. Hof, Mount Sinai School of Medicine, USA

\section{Reviewed by:}

Leah Krubitzer, University of

California, USA

Dan Uhlrich, University of

Wisconsin-Madison Medical School,

USA

\section{*Correspondence:}

Elena Borra, Dipartimento di

Neuroscienze, Sezione di Fisiologia,

Università di Parma, Via Volturno 39,

1-43100 Parma, Italy.

e-mail: elena.borra@unipr.it
Non-extrastriate projections to area $\mathrm{V} 1$ in monkeys, now demonstrated by several anatomical studies, are potential substrates of physiologically documented multisensory effects in primary sensory areas. The full network of projections among association and primary areas, however, is likely to be complex and is still only partially understood. In the present report, we used the anterograde tracer biotinylated dextran amine to investigate projections to areas $\mathrm{V} 1$ and $\mathrm{V} 2$ from subdivisions of the parietal association cortex in macaque. Parietal cortex was chosen to allow comparisons between projections from this higher association area and from other previously reported areas. In addition, we were interested in further elucidating pathways to areas $\mathrm{V} 1$ and $\mathrm{V} 2$ from parietal areas, as potentially contributing to attention and active vision. Of eight cases, three brains had projections only to area $\mathrm{V} 2$, and the five others projected to both areas $\mathrm{V} 1$ and $\mathrm{V} 2$. Terminations in area $\mathrm{V} 1$ were sparse. These were located in supragranular layers I, II, upper III; occasionally in IVB; and in layer VI. Terminations in V2 were denser, and slightly more prevalent in the supragranular layers. For both areas, terminations were in the calcarine region, corresponding to the representation of the peripheral visual field. By reconstructions of single axons, we demonstrated that four of nine axons had collaterals, either to $\mathrm{V} 1$ and $\mathrm{V} 2(n=1)$ or to area $\mathrm{V} 1$ and a ventral area likely to be TEO $(n=3)$. In area $\mathrm{V} 1$, axons extended divergently in layer $\mathrm{VI}$ as well as layer I. Overall, these and previous results suggest a nested connectivity architecture, consisting of multiple direct and indirect recurrent projections from association areas to area V1. Terminations in area V1 are not abundant, but could be potentiated by the network of indirect connections.

Keywords: anterograde tracers, feedback, multimodal, visual field

\section{INTRODUCTION}

An increasing number of physiological studies in humans and monkeys have provided evidence of multisensory processing in primary or early sensory areas (Lomber et al., 2010; Molholm and Foxe, 2010; Shams and Kim, 2010). Auditory-visual (e.g., Ghazanfar et al., 2005), auditory-somatosensory (Foxe et al., 2002), and visual-somatosensory interactions (Merabet et al., 2008) have been extensively investigated. The anatomical substrates of these interactions are likely to include projections between primary

\footnotetext{
Abbreviations: A1, primary auditory area; AP, anteroposterior (stereotactic direction); BDA, biotinylated dextran amine; CF, calcarine fissure; DV, dorsoventral (stereotactic direction); IPL, inferior parietal lobule; ML, mediolateral (stereotactic direction); MT, middle temporal area; Opt, cortical area Opt of Pandya and Seltzer (1982); OTS, occipito-temporal sulcus; PEc, cortical area PEc of Pandya and Seltzer (1982); PF, cortical area PF of Pandya and Seltzer (1982); PFG, cortical area PFG of Pandya and Seltzer (1982); PG, cortical area PG of Pandya and Seltzer (1982); S1, primary somatosensory area; SPL, superior parietal lobule; STP, superior temporal polysensory area of Bruce et al. (1981); TEO, cortical area TEO of Von Bonin and Bailey (1947); TF, cortical area TF of Von Bonin and Bailey (1947); TH, cortical area TH of Von Bonin and Bailey (1947); V2L, lateral part of the secondary visual area in rodents; V2M, medial part of the secondary visual area in rodents; WGA-HRP, wheat germ agglutinin-horseradish peroxidase conjugated.
}

cortices of different modalities as well as from cortical association areas to primary cortex. Projections to area V1 have been demonstrated from both early auditory and multisensory association areas in several anatomical studies in monkeys (auditory cortex: Falchier et al., 2002; Rockland and Ojima, 2003; area STP in the superior temporal sulcus: Falchier et al., 2002; perirhinal cortex: Clavagnier et al., 2004; and areas TF and TH in the parahippocampal gyrus: Doty, 1983; Kennedy and Bullier, 1985; Rockland and Van Hoesen, 1994; and in New World monkeys, Lyon and Kaas, 2002). Projections have been reported from visual area V2 to nonprimary auditory cortex in monkey (Rockland and Ojima, 2003; Falchier et al., 2010), sparsely between areas V1 and several auditory areas in ferrets (Bizley et al., 2007), and from areas V2M and V2L to primary auditory cortex in rodents (rats: Smith et al., 2010; mice: Banks et al., 2011). Overall, results so far suggest that there are cross-modal projections originating from both association and primary cortical areas, but that those from association cortices are more abundant.

In the present report, we use anterograde tracers to investigate projections to areas V1 and V2 from subdivisions of parietal association cortex in monkeys. The parietal cortex is characterized by a high degree of multisensory and sensorimotor integration 
for action organization (Fogassi and Luppino, 2005; Rozzi et al., 2008; see Table 1). Thus, we were interested in identifying features of parieto-visual projections, as possible substrates of phenomena such as shifting spatial attention (see, e.g., Andersen and Buneo, 2002; Berman and Colby, 2009). Anterograde tracers provide direct evidence of density of terminations; and the injection sites can be more easily confined to a given area, in contrast with retrograde tracers in area $\mathrm{V} 1$, which often involve adjoining area V2. We have also carried out reconstructions of nine single axons in order to provide new information about detailed topography, possible collateralization to multiple areas, extent of terminal field, and laminar organization. Some of these data were presented schematically in a previous short report (Rockland and Ojima, 2003).

\section{MATERIALS AND METHODS}

Eight young adult macaque monkeys received injections of the anterograde tracer biotinylated dextran amine (BDA) in different parts of the inferior parietal lobule (IPL) and in the superior parietal lobule (SPL). Procedures were in accordance with institutional guidelines, as specified in approved Animal Care and Use Forms (University of Iowa).

Surgery was carried out under sterile conditions after the animals were deeply anesthetized with barbiturate anesthesia (Nembutal, $25 \mathrm{mg} / \mathrm{kg}$ i.v.) preceded by a tranquilizing dose of ketamine $(11 \mathrm{mg} / \mathrm{kg}$ i.m.). Cortical areas of interest were localized by direct visualization, subsequent to craniotomy and durotomy, in relation to sulcal landmarks (i.e., intraparietal sulcus and lateral fissure). Injections of BDA [ $10 \%$ in $0.0125 \mathrm{M}$ phosphatebuffered saline (PBS; 1:1 mix of 3,000 and 10,000 MW), 0.5$2.0 \mu \mathrm{l}$ per injection; Molecular Probes] were made by pressure via a $10-\mu l$ Hamilton syringe. One to three injections were made, with total tracer volumes of $1.0-2.5 \mu l$ per craniotomy. Animals

\section{Table 1 | Functional properties of the injected areas.}

\begin{tabular}{|c|c|}
\hline Area & Properties \\
\hline PF & $\begin{array}{l}\text { Organization of eating behavior. Somatosensory information instru- } \\
\text { mental to the execution of appropriate food-related or explorative } \\
\text { mouth motor acts }{ }^{1}\end{array}$ \\
\hline PFG & $\begin{array}{l}\text { Organization of hand and hand-to-mouth actions, aimed to manipu- } \\
\text { late and interact with objects on the basis of their physical prop- } \\
\text { erties, their location in peripersonal space and their behavioral }_{\text {value }^{1}}\end{array}$ \\
\hline$P G$ & $\begin{array}{l}\text { Organization and control of "reaching-with-the arm and the eye" at } \\
\text { the limit between the peri- and extrapersonal space, on the basis of } \\
\text { several visual information about the position, motion, and behavioral } \\
\text { values of the target stimuli }{ }^{1}\end{array}$ \\
\hline Opt & $\begin{array}{l}\text { Coding of eye- and arm-directional visuomotor signals. Integration } \\
\text { and transformation of retinal and extra-retinal signals to head-, body- } \\
\text { or world-centered coordinates }{ }^{2}\end{array}$ \\
\hline PEc & $\begin{array}{l}\text { Somatosensory and visuomotor processing for the early stages of } \\
\text { motor control for arm movements toward targets in the peripersonal } \\
\text { space }^{3}\end{array}$ \\
\hline
\end{tabular}

${ }^{1}$ Rozzi et al. (2008); ${ }^{2}$ Battaglia-Mayer et al. (2007); ${ }^{3}$ Breveglieri et al. (2008). were administered postsurgical doses of antibiotics and analgesics, allowed to recover, and survived 18-29 days after injections. They were then re-anesthetized, given an overdose of Nembutal $(75 \mathrm{mg} / \mathrm{kg})$ and perfused transcardially, in sequence, with saline containing $0.5 \%$ sodium nitrite, $4 \%$ paraformaldehyde, and chilled $0.1 \mathrm{M}$ phosphate buffer with 10,20, and 30\% sucrose.

Brains were cut serially in the coronal plane by frozen microtomy (at $50 \mu \mathrm{m}$ thickness) and processed histologically for BDA (Ding et al., 2000). To develop BDA, tissue was reacted for 20$24 \mathrm{~h}$ in avidin-biotin complex (ABC Elite kits; Vector Laboratories, Burlingame, CA, USA) at room temperature (one drop of reagent per $7 \mathrm{ml}$ of $0.1 \mathrm{M}$ PBS with $0.5 \%$ Triton-X). In the final step, BDA was demonstrated by 3,3'-diaminobenzidine tetrahydrochloride $(\mathrm{DAB})$ histochemistry with the addition of $0.5 \%$ nickel-ammonium sulfate (yielding a black reaction product).

The parietal injections as a group covered almost the full extent of the IPL (see Figure 1), from caudal (Cases P5 and 35) to rostral (Case 28). In correlation with previous studies, these injections were considered to involve parts of areas Opt, PG, PFG, and PF (Pandya and Seltzer, 1982; Gregoriou et al., 2006; and see review in Lewis and Van Essen, 2000). One injection was placed in SPL, area PEc (Pandya and Seltzer, 1982). All the injection sites used in this study were restricted to the cortical gray matter, and involved the entire cortical thickness or at least layers II-upper VI. Results from these injections have been used also in previous studies (Rockland and Van Hoesen, 1999; Ding et al., 2000; Rockland and Ojima, 2003; Zhong and Rockland, 2003).

Axon reconstruction was carried out as previously described (Ding et al., 2000; Rockland, 2002; Zhong and Rockland, 2003). That is, sections were scanned with a $10 \times$ or $20 \times$ objective to identify labeled processes in the gray matter. Candidate axons were then reconstructed through sequential sections, by aid of a camera lucida microscope attachment. Both intermediate $(200 \times)$ and higher magnifications $(400 \times$ or $1,000 \times)$ were used selectively, and data images on paper were adjusted and merged manually by xerox or by Adobe Photoshop, after scanning and digitizing. Axon dimensions [anteroposterior (AP), dorsoventral (DV), and mediolateral (ML)] are derived as a "hollow" or bounded figure. Usually, terminations are not continuously distributed within this bounded space, but occur sporadically and in patches. Reconstructions were deemed complete or "reasonably complete" if we could identify the main axon as it traveled from the white matter into the cortex, and if we could verify that we had traced various branches to their end point. The criteria for end points were: (1) the apparent end point was not at the top or bottom of the section, or (2) the profile of interest could no longer be found in the adjacent section. Incomplete branches are designated by black circles.

Both areas V1 and V2 are easily identified, except for the rostral border of V2. This border was conservatively judged as about $6.0 \mathrm{~mm}$ from the border with $\mathrm{V} 1$, and further evaluated with reference to other studies (Gattass et al., 1981; Van Essen et al., 1984; Horton et al., 1999). In this report, we use "early sensory areas" to designate V1 and V2 together. "Association cortex," unless otherwise specified, is used globally for both higher and lower order areas, as defined by synaptic proximity to the primary area.

The photomicrographs shown in the present study were obtained by capturing images directly from the sections using 


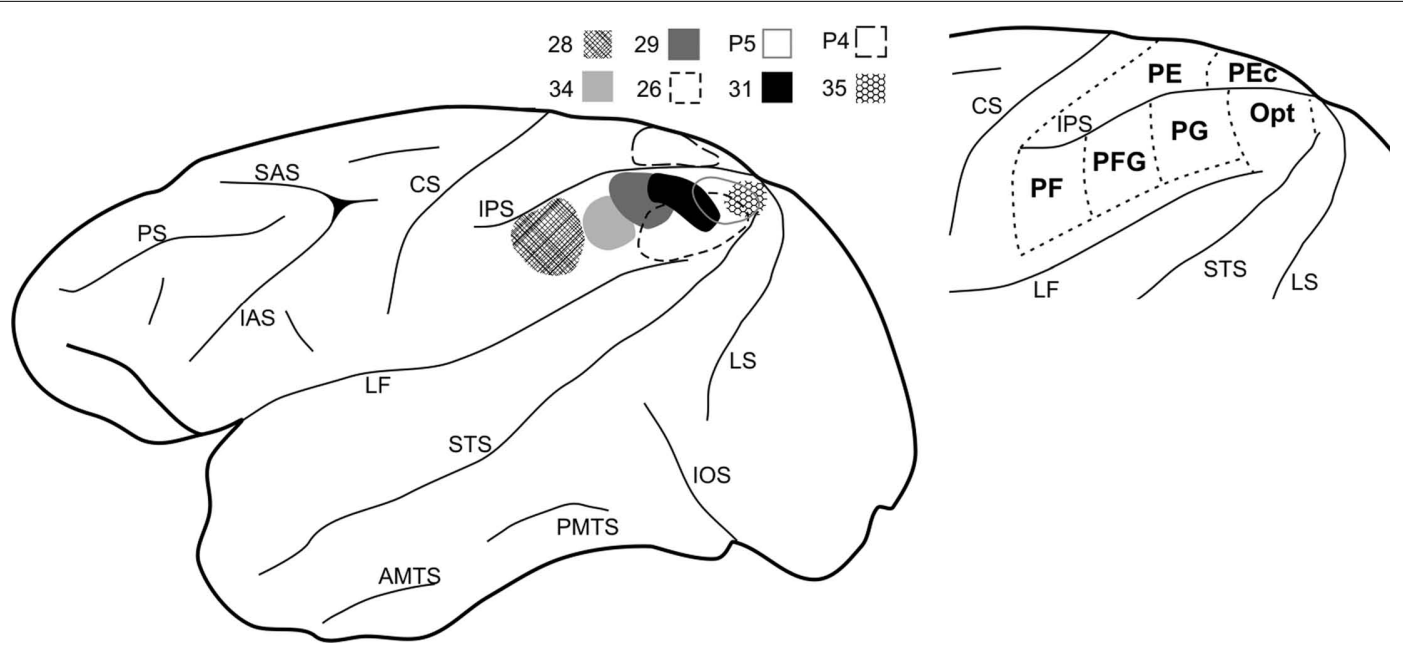

FIGURE 1 | Summary of the parietal injection sites used for this study. At left, the BDA injections $(n=8)$ are schematically mapped onto a lateral view of a macaque monkey left hemisphere. A schematic mapping of parietal lobe subdivisions is shown at the right, as adapted from Pandya and Seltzer (1982) and Gregoriou et al. (2006). AMTS, anterior middle temporal sulcus; CS, central sulcus; IAS, inferior arcuate sulcus; IOS, inferior occipital sulcus; IPS, intraparietal sulcus; LF, lateral fissure; LS, lunate sulcus; PMTS, posterior middle temporal sulcus; PS, principal sulcus; SAS, superior arcuate sulcus; STS, superior temporal sulcus. a digital camera (AxioCam HRC) attached to the microscope (Zeiss Axioskop 2 plus). Individual images were then imported into Adobe Photoshop so that they could be processed, eventually assembled into digital montages, and reduced to the final enlargement. In most cases, image processing required lighting, brightness, and contrast adjustments. These were matched to the real microscope image.

\section{RESULTS}

GLOBAL TOPOGRAPHY OF PARIETAL PROJECTIONS TO THE CALCARINE FISSURE (CF)

Seven large injections were made so as to cover most of the IPL (Figure 1). The rostralmost injection was at the border of areas PF/PFG (Case 28), two injections were judged to be fully in area PG (Cases 29 and 34), three injections involved part of both areas PG and Opt (Cases 26, 31, and P5), and one injection was restricted to area Opt (Case 35). One injection was located in the SPL, in area PEc (Case P4).

Among these eight cases, the smaller injections involving only part of Opt (Case 35) or PG (Cases 29 and 34), had projections only to area V2 in the CF. The five other injections, projected to both areas V1 and V2. None projected only to V1. Results are summarized in Table 2 .

\section{Projections to area V2}

Projections from the two PG cases (29 and 34) were principally dorsal in the CF (Figure 2, Case 29). From the rostral part of V2, terminations were detected almost continuously toward the caudal pole for $9.0 \mathrm{~mm}$ (Case 34) or $11.0 \mathrm{~mm}$ (Case 29). At rostral levels, terminations were at or near the border with V1, and more caudally, these extended onto the medial interhemispheric wall. In Case 34, but not 29, there was an additional small cluster of terminations in ventral V2, rostrally, near the border with V1.
Table 2 | Presence and dorsal/ventral location in the CF of the labeling in V1 and V2.

\begin{tabular}{llll}
\hline Case & Injected area & V1 & V2 \\
\hline 28 & PF/PFG & d, $v$ & d \\
34 & PG & - & d, $v$ \\
29 & PG & - & d \\
35 & Opt & - & d \\
31 & PG/Opt & d, $v$ & d, $v$ \\
26 & PG/Opt & d, $v$ & d, $v$ \\
P5 & PG/Opt & d, $v$ & d, $v$ \\
P4 & PEc & d & d \\
\hline
\end{tabular}

Bold indicates the prevalent location of the labeling.

The Opt injection (Case 35) also produced terminations in dorsal V2. These were at the border with V1, rostrally, and persisted for about $5.0 \mathrm{~mm}$ caudally. With caudal progression, these shifted away from the border, to the adjacent medial wall.

\section{Projections to areas V1 and V2}

Figure 2 shows two representative cases (28 and P5) of the termination pattern in area V1. That is, terminations occurred far rostrally in the CF and continued caudally for about $12.0 \mathrm{~mm}$ (Cases 26 and P5) or $7.0 \mathrm{~mm}$ (Case P4, injection in PEc). With caudal progression, terminations shifted from the dorsal V1/V2 border to the depth of the CF. In Case 31, however, the terminal focus persisted as a strip, about $5.0 \mathrm{~mm}$ long, adjoining the border with V2 and did not extend to the rostralmost V1.

The terminal focus in V2 mirrored that in V1 (Figure 2); that is, terminations (1) were at the upper bank of the CF, (2) were located at the V1/V2 border rostrally, (3) shifted onto the medial interhemispheric wall with caudal progression, and (4) extended along a strip of cortex about 7-8 mm long. In Case P4 (see Figure 4), with 


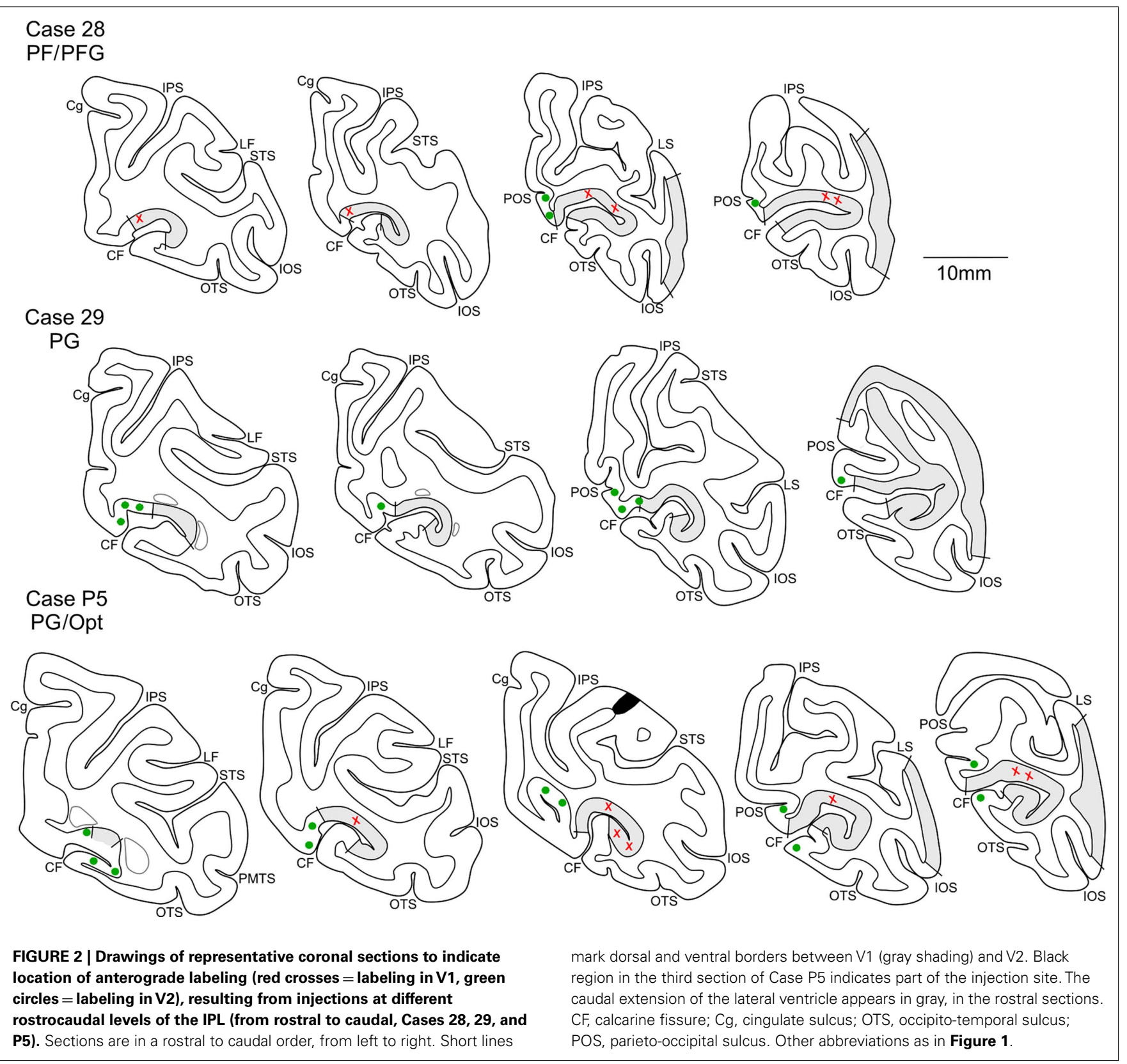

an injection in area PEc, terminations were restricted to a smaller zone, only about $2.0 \mathrm{~mm}$ long. For Cases P5 and 26 (injections laterally in PG and adjoining Opt), some terminations also occurred in ventral V2 (Figure 2, for Case P5), forming two foci. One rostral focus was near the border with area prostriata, extended caudally for only about $2.0 \mathrm{~mm}$, and remained at the border location. A second focus occurred $3-5 \mathrm{~mm}$ caudal (or, 5-7 $\mathrm{mm}$ from the rostral border of V1), and was detected for about 7-9 $\mathrm{mm}$ (Figure 5, for Case 26).

\section{Relation to visual field}

Extrapolating from published visual field maps (Gattass et al., 1981; Van Essen et al., 1984; Horton et al., 1999), we can infer: (1) that areas PF-PFG and PG-Opt project to V1 from the far periphery representation to about $20^{\circ}$ of eccentricity $(12 \mathrm{~mm}),(2)$ that there is a strong preference for the lower visual field (upper bank of the CF), (3) that there is some preference for the vertical meridian representation, especially in the far periphery (rostral $\mathrm{CF}$ ), and (4) that the terminal focus typically shifts away from the vertical meridian representation with caudal progression. Similar conclusions hold for area V2, except that some parts of area PG/Opt have projections as well to the upper visual field (lower bank of the CF). Area PEc appears to have less extensive projections than the areas in the IPL. These are directed to the lower vertical meridian representation in $\mathrm{V} 1$ and $\mathrm{V} 2$, from the far periphery into about $25^{\circ}$ of eccentricity.

\section{Laminar distribution of terminations and cells}

Terminations in area V1 were in supragranular layers I, II, upper III, and in layer VI. As illustrated below in Figures 4A,B, and 
$\mathbf{5 A}$, reconstructions of individual axons revealed that terminations could be bistratified, but there was also one axon with terminations exclusively in layer VI. Boutons could be detected in the subgriseal white matter (Figure 3F), and along the trunk of the axon as it ascends to the pia. Surprisingly, a few boutons occurred also in layer IV (Figure 3A). In V2, terminations were denser, with some slight prevalence for the supragranular layers (Figure 3E). Again, a few boutons occurred along the main ascending axon trunk, including in layer IV. Some very sporadic retrograde labeling was noticed in dorsal V2, mainly in deep layer III (Cases 31 and 35). This can be taken as evidence of reciprocal projections from V2 to the injection site. Since BDA only sporadically results in retrograde labeling ("BDA gives a capricious retrograde labeling," Vercelli et al., 2000), the number of labeled cells is likely to be less than what would be seen after injections of a conventional retrograde tracer in parietal areas (compare Figure 4 in Cavada and Goldman-Rakic, 1989).

\section{SINGLE AXON RECONSTRUCTION}

Nine axons were analyzed by serial section reconstruction, from Cases P4, P5, 26, and 28 (Figures 4 and 5). Four partial reconstructions (of segment length $\sim 2.0 \mathrm{~mm}$ ) were available for comparison. By this approach, individual arbors are revealed to be highly divergent (range: $1.5-3.5 \mathrm{~mm} \mathrm{AP}, 4.0-12.0 \mathrm{~mm} \mathrm{DV}$ ). The nine axons (with one additional, illustrated in Figure 3, Rockland and Ojima, 2003) exhibited a high degree of non-uniformity in their specific geometry and laminar distribution. In addition, reconstruction showed that some axons could be restricted to V1, whereas others had collaterals to V1 and an extrastriate area (V2 or TEO). For five axons with apparent arborization only in V1, the possibility remains that there are collaterals to $\mathrm{V} 2$ or another areas, from branches deep in the white matter.

One axon from P5 (Figure 4A) had three distinct clusters restricted to layer VI of area V1. These each measured slightly $>1.0 \mathrm{~mm} \mathrm{DV} \times 0.3-0.75 \mathrm{~mm} \mathrm{AP}$, with a center-to-center spacing of about $2.0 \mathrm{~mm}$. The number of boutons was counted as 2,880 .

Two axons had terminations in V1 along with an additional collateral beyond the CF. This was followed in the white matter to a dense termination focus in the occipito-temporal sulcus (OTS), likely to be area TEO (see also Figure 3, Rockland and Ojima, 2003). One of these axons had terminations in layer I alone $(0.5 \mathrm{~mm}$ $\mathrm{DV} \times 2.5 \mathrm{~mm}$ AP; Figure 4C; total boutons = 1,722); and the other (not illustrated) had a small collateral in layer VI as well as the main terminal focus in layer I $(0.5 \mathrm{~mm} \mathrm{DV} \times 1.5 \mathrm{~mm} \mathrm{AP})$. A third axon, previously illustrated in Figure 3 of Rockland and Ojima (2003), terminated in layer VI alone $(1.0 \mathrm{~mm} \mathrm{DV} \times 0.75 \mathrm{~mm} \mathrm{AP})$.

Five axons had terminations in layers I, II, and VI of area V1 (Figures 4B, 5A). Terminations often formed small arbors, especially in layer VI. These were of variable size and spacing, with some tendency for a center-to-center spacing of about $2.0 \mathrm{~mm}$. For the axon shown in Figure 4B, 1,696 boutons were scored in the upper layers and 1,072 in the deeper layers (total =2,768). One of these axons (Case 28; not illustrated) had three small, spatially separate arbors in layer IVB, as well as in layers I, II, and VI.

Finally one axon (Case 26) had terminations in both areas V1 and V2. The portion in area V1 was restricted to a small collateral in layer I (Figure 5B, section 80), but the main trunk continued rostrally for another $10.0 \mathrm{~mm}$, into $\mathrm{V} 2$, where five further branches were identified (sections 280, 303, 323, 351). The branches were each separated by approximately $1.0 \mathrm{~mm}$ AP, but finer branching and terminations could not be followed in this case.

\section{Relation to visual field}

Five of the axons in our sample had an asymmetrical spatial extent, estimated as slanted-perpendicular to the horizontal meridian. One axon (Figure 4B) was more symmetrical, having extension measured as $3.1 \mathrm{~mm} \times 3.0 \mathrm{~mm}$. The three axons from Case P5 with collaterals to the OTS region had arbors that were more restricted $(\sim 0.5 \mathrm{~mm})$, but with a slight bias for the AP dimension (1.5-2.5 mm).

The visual map as extrapolated from the literature can be expected to vary in the individual animals. However, as the horizontal meridian is usually located just dorsal to the fundus of the CF (Gattass et al., 1981), we can note that the axon in Figure 4A may lie near the horizontal meridian; the axon in Figure 4B closer to the lower vertical meridian representation, and the axon in Figure 4C, in the upper visual field. Although the global termination pattern is biased to the lower visual field, many of the axon reconstructions are close to the location of the horizontal meridian.

Several of the axons had multiple arbors, arranged in a patchy distribution. Patchiness was particularly conspicuous for arbors in layer VI. The axon illustrated in Figure 4A had three arbors in layer VI; the axon in Figure 5A had three rather large arbors in layer VI (about $0.5 \mathrm{~mm}$ edge to edge) and three smaller ones. Layer VI arbors are typically offset from those in the upper layers. The patches in layer VI are consistent in their spacing (about $2.0 \mathrm{~mm}$ center-to-center) with that of a left-eye, right-eye hypercolumn.

\section{DISCUSSION}

Several earlier studies reported that area V2 in monkeys was connected with frontal or parietal association cortex. Most of these studies reported labeled neurons in area V2 after retrograde tracer injections, in frontal cortical areas (Barbas, 1988; Schall et al., 1995) or parietal areas (Cavada and Goldman-Rakic, 1989; Baizer et al., 1991; Lewis and Van Essen, 2000). Neurons in V2 were located in the vicinity of the CF, corresponding to the far peripheral visual field representation, consistent with the present findings. In one study, anterogradely labeled terminations were remarked in calcarine area V2, after injections of tritiated amino acids in the frontal eye fields (Stanton et al., 1995). None of this earlier work detected connections to or from area V1. This is not surprising, since the anterograde signal from tritiated amino acids or WGAHRP is dustlike, and would be hard to distinguish from noise in the case of light projections, such as occur in area V1. Moreover, as stated above, most of these earlier investigations used retrograde tracer injections in parietal or frontal areas. If the projections to area V1 are not reciprocal, no labeled neurons would result in V1.

In more recent work, projections have been documented to primary auditory cortex (A1) in rodents from extrastriate visual areas (Smith et al., 2010; Banks et al., 2011); to A1 in ferrets from both primary visual and higher order visual areas, but only sparsely from the former (Bizley et al., 2007); and to caudal auditory areas 

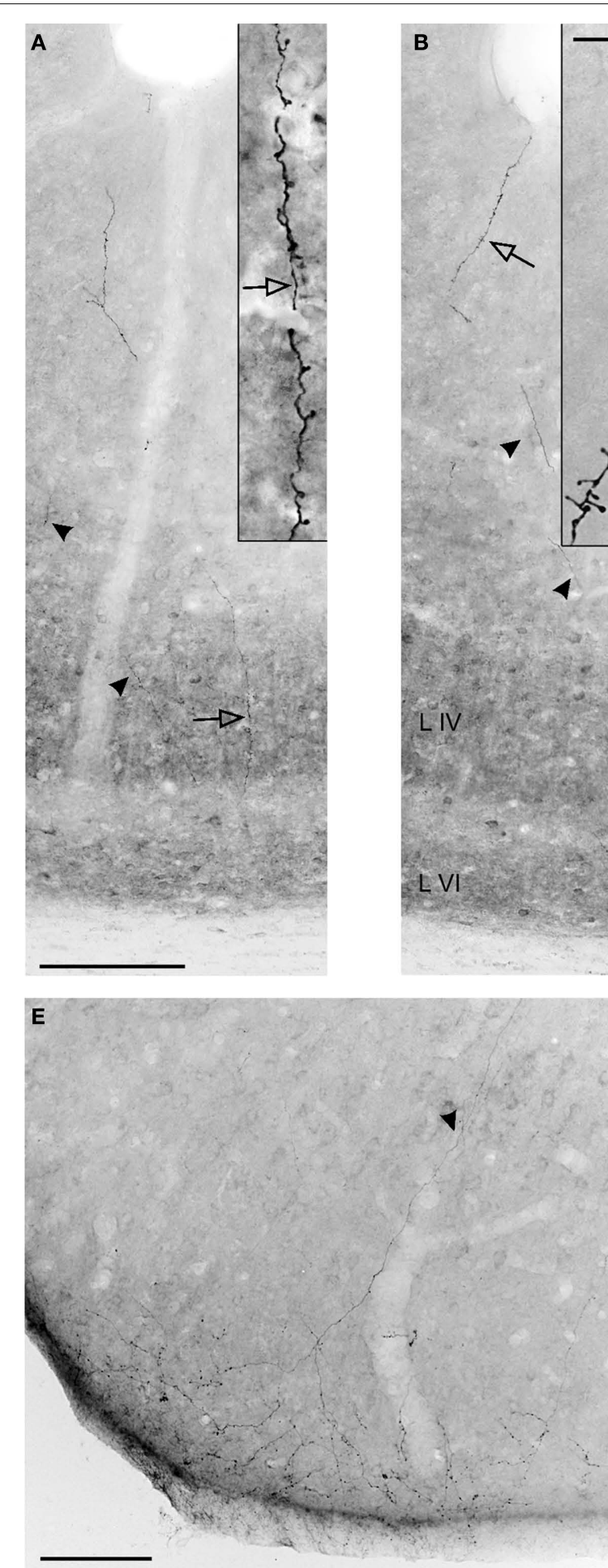

FIGURE 3 | Photomicrographs of axons in the CF, anterogradely labeled by BDA injections in IPL. (A,B) Two sequential sections from ventral V1 (see Figure $\mathbf{4 C}$ ). Labeled segments are visible in all layers (arrowheads). Higher magnification (insets) show terminations in layer IV (A) and I, II (B), where the hollow arrows point to corresponding features at the two magnifications. (C) Another field of BDA labeling in V1. Terminations in layer I (hollow arrow) are shown at higher magnification in (D). (E) A field of BDA-labeled terminations in dorsal V2. Arrowhead

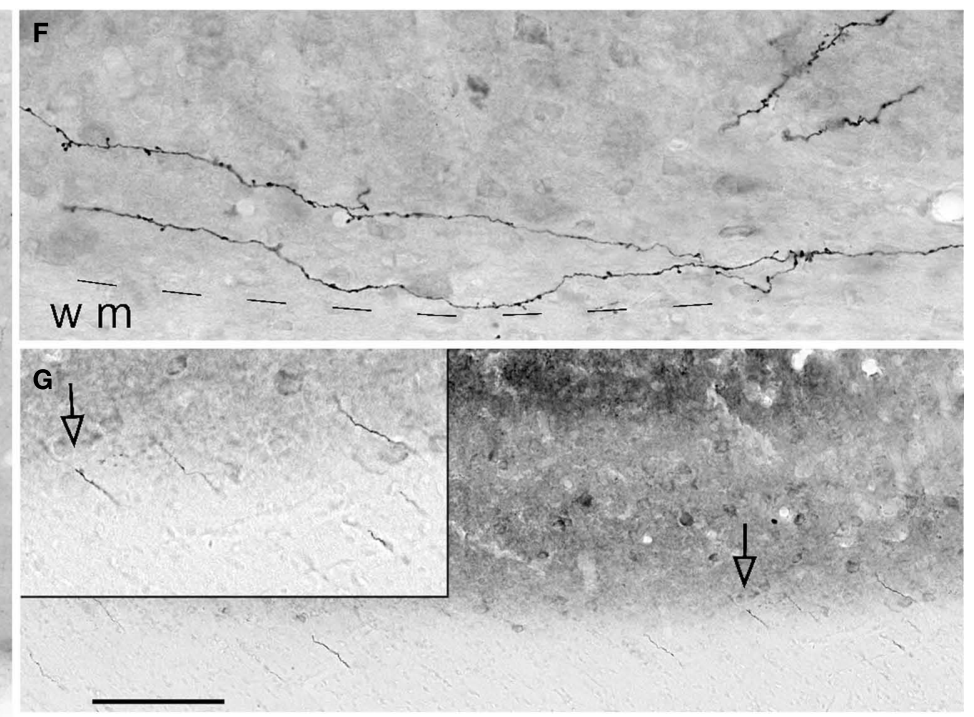

indicates an ascending axon segment. (F) BDA-labeled terminations in layer V of area $\mathrm{V} 1$. The dashed line indicates white matter border (WM). (G) A field of labeled axon segments in the white matter subjacent to V1. Inset, from hollow arrow, shows five segments at higher magnification. (E) is from Case 28, all the other examples are from Case P5. Scale bar in (A) applies to (B) and (C) $(200 \mu \mathrm{m})$; scale bar in the inset in (B) applies to inset in (A) $(10 \mu \mathrm{m})$; scale bar in (D), applies to (F) and inset in (G) $(100 \mu \mathrm{m})$. Scale bars in (E) and (G) $=100 \mu \mathrm{m}$ 
A
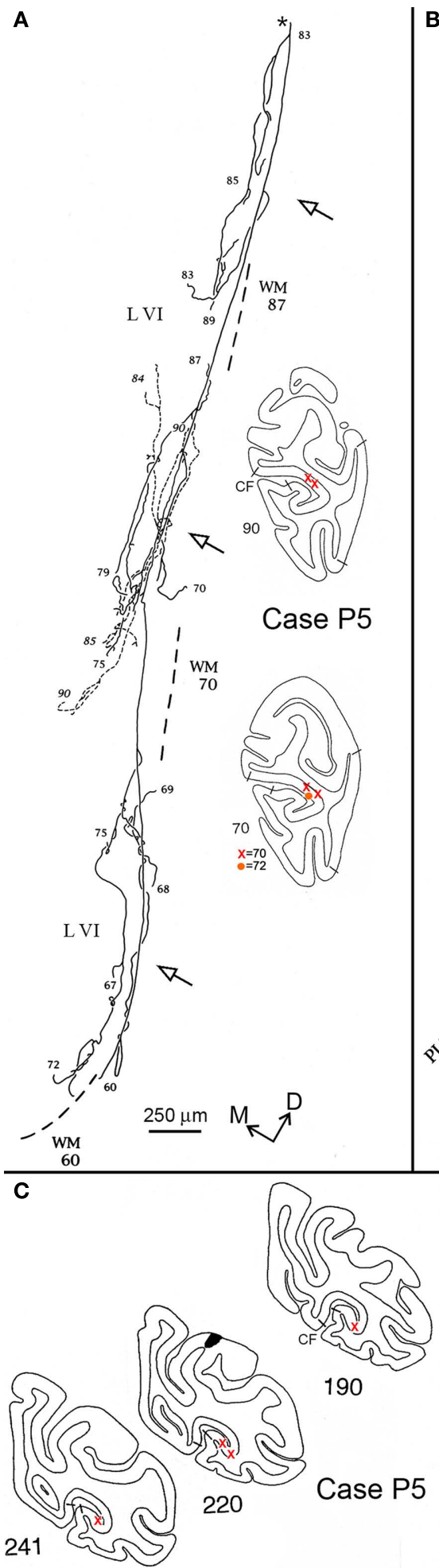

B
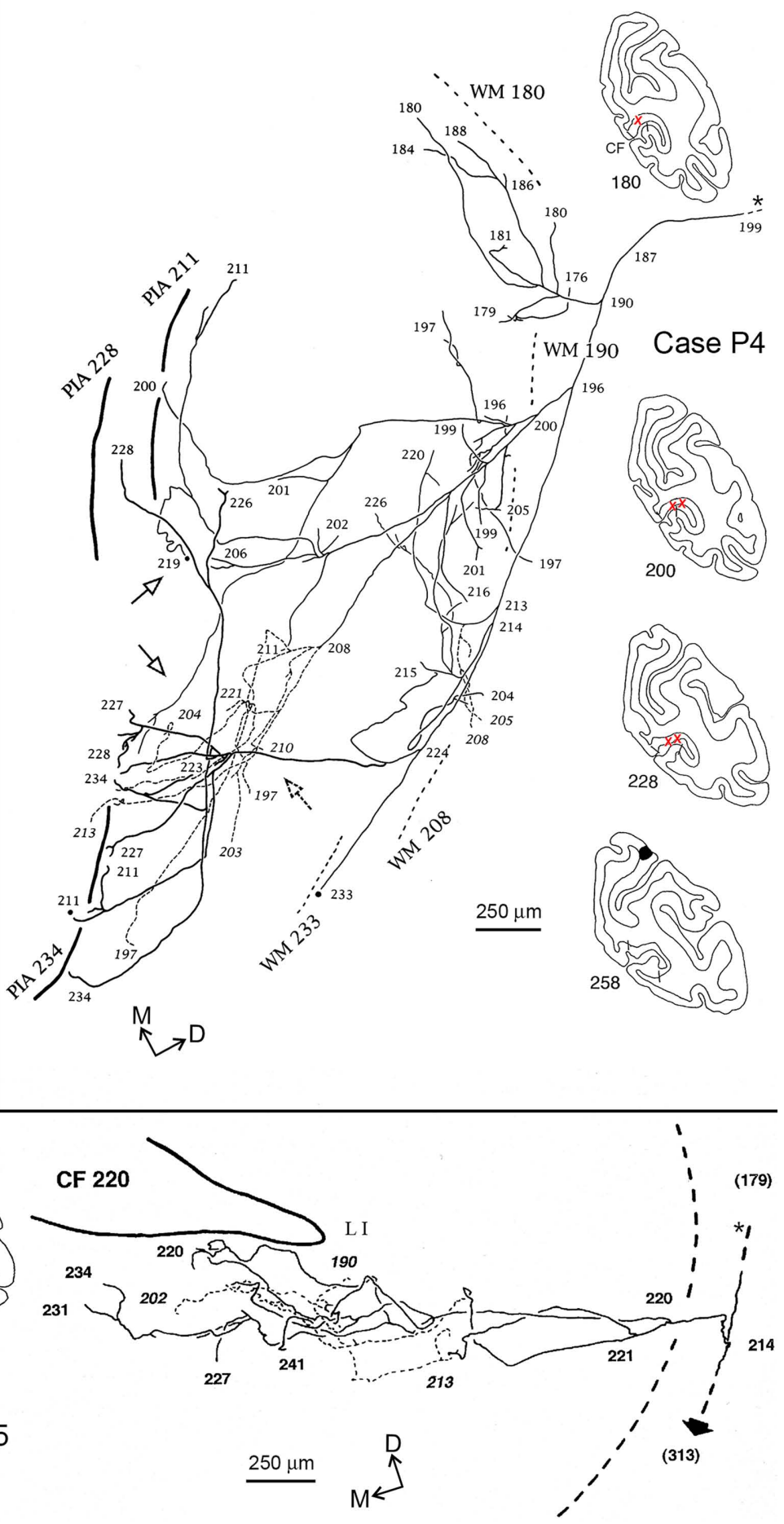

FIGURE 4 | Continued.

from visual area V2 and prostriata in monkeys (Falchier et al., 2010). In the prairie vole, a behaviorally specialized rodent, direct connections have been shown from both V1 and S1 to A1, and from A1 and S1 to V1, but these are described as "moderate to sparse" (Campi et al., 2010); and in the gerbil, from both S1 and V2 to A1 (Budinger et al., 2006). In monkeys, anterograde tracer 
FIGURE 4 | Camera lucida reconstructions of three axons in area V1 (CF), anterogradely labeled by injections of BDA in PG/Opt, Case P5 (A,C), and PEc, Case P4 (B). The reconstructions are tilted slightly, relative to the section outlines, for the sake of formatting, and correspond to the orientation of the dorso-medial directionality compass; for the coronal section outlines dorsal is at the top. The axon in (A) extends over a territory measuring about $5.0 \mathrm{~mm}$ DV by $1.5 \mathrm{~mm}$ AP. Three distinct foci can be discerned (hollow arrows), all restricted to layer $\mathrm{VI}$, and separated by $1.5-2.0 \mathrm{~mm}$, center-to-center. The axon in $(\mathbf{B})$ is again divergent, and extends over a territory measuring $3.1 \mathrm{~mm} \mathrm{ML}$ by $3.0 \mathrm{~mm}$ AP. For this axon, terminations are distributed in both the supraand infragranular layers. Three supragranular foci (hollow arrows) can be identified, separated by 1.0-1.2 mm center-to-center; and there is also a suggestion of three infragranular foci. The axon in (C) has terminations almost confined in layers I, II (except for a few boutons along the main axon, in layer IV, see Figure 3A). Its terminations are slightly more local, concentrated over a territory of $0.5 \mathrm{~mm}$ DV by $2.5 \mathrm{~mm}$ AP. Also distinctive, a second collateral (short, solid arrow) continues to a projection focus in the OTS (at section 313), approximately $5 \mathrm{~mm}$ rostral. For this axon, the main axon was followed caudally for another $1.7 \mathrm{~mm}$ (to section 179), toward the injection site. (See photomicrograph, Figures $\mathbf{3 A}, \mathbf{B}$ ). In this and the next figure, the asterisk and small dashes denote the main axon [section 83 in (A), 199 in (B), 179 in (C)]. Numbers correspond to individual sections, where larger numbers are rostral. The black regions in sections 258 [in (B)] and 220 [in (C)] correspond to part of the injection site. The reconstruction was deemed complete, except as designated by solid black circles. The approximate location of the axons is marked on the numbered coronal section outlines. Short lines on the external border of the cortex indicate the $\mathrm{V} 1-\mathrm{V} 2$ border. White matter (WM) is marked by dashed lines, for the section level indicated by the number. A broken line of short dashes (with numbers in italics) is used to distinguish segments of axons which are offset in the z-axis, but appear to overlap in this collapsed, 2-dimensional image. In (B) and (C), thick lines indicate the pial surface ("pia"), drawn at the section indicated by the number. Orange circles and red crosses indicate the location of labeling both in V1 but in different sections. Other conventions as in Figure 2. injections in both early auditory areas (Rockland and Ojima, 2003) and parietal association areas (present report) resulted in denser terminations in V2 than in V1. Retrograde tracer injections in the calcarine area in monkey result in retrogradely labeled neurons in both primary and association auditory cortex (Falchier et al., 2002), but the injections were large and may have involved some of V2.

Single axon reconstruction reveals that the axons projecting from parietal areas to V1 are highly divergent, with the exception of a small group shown to have collaterals to V1 and an extrastriate area in the OTS. This high degree of divergence is characteristic of projections to layer I, as often described for feedback projections within the visual system; for example, projections from area MT (Rockland and Knutson, 2000), area TEO (Rockland et al., 1994) or more anterior temporal areas (Rockland and Drash, 1996). One axon in our present sample had demonstrable branches in both area V1 and V2, also consistent with previous reports of collateralized visual feedback projections (Rockland and Knutson, 2000). Projections to A1 from extrastriate visual areas in the rat are shown by axon reconstruction to travel for considerable distance in layer I (Smith et al., 2010).

Unusually, however, the axons in our sample could have terminations along the ascending portion of the main trunk (Figure 3). This has been reported for at least one other layer I-targeting projection; namely, projections from hippocampal CA1 to frontal cortex in monkeys (Zhong et al., 2006). The parallel fibers in the cerebellum also have boutons along their ascending portion; and in one interpretation, this ascending portion has been argued to have a greater functional influence in Purkinje cell excitation than the parallel fiber beam (Rokni et al., 2008).

Six of the reconstructed axons in this study had a distinct asymmetry, with a significantly greater extension in the DV dimension. This appears as outlining the upper and lower banks of the CF, when it is sectioned coronally; that is, traveling away from the vertical meridian representation at the V1/V2 border, deeper into the visual field, toward the horizontal meridian representation. Another feature evident from the single axon analysis was a rather distinct modularity, especially in layer VI. This was most conspicuous for the axon illustrated in Figure 4A, where arbors were confined exclusively to layer VI; but the profiles in Figures $4 \mathrm{~B}$ and
5A also had patchy terminal foci in layer VI. These patches are separated by approximately $2.0 \mathrm{~mm}$ center-to-center, which could be correlated with the classical hypercolumns and thus argue for a specifically visual function.

Another important clue to the functional importance of these connections would seem to be the selective targeting of the peripheral visual field and the lower visual field representation. Functional specialization of the lower and upper visual quadrants is well known (Previc, 1990): the lower visual quadrant (dorsal cortex) has been linked with global vision in peripersonal space, whereas the upper visual quadrant (ventral cortex) is associated with local perceptual mechanisms and far visual space (Previc, 1990; Christman and Niebauer, 1997). It is reasonable that parietal areas, considered as concerned with sensorimotor integration and motor planning in near peripersonal space (Fogassi and Luppino, 2005) favor the dorsal CF.

Specialized connectivity in relation to the peripheral visual field is not unusual. Differential projections have been identified in the marmoset monkey for area MT, in its peripheral and central visual representations (Palmer and Rosa, 2006). In macaque monkeys, the projections from MT to V1 have been shown to have dual, eccentricity related laminar patterns: those to peripheral field representations of V1 terminate in layers I, IVB, and VI, but those to more central representations terminate only in layers IVB and VI (Maunsell and Van Essen, 1983; Ungerleider and Desimone, 1986; Shipp and Zeki, 1989; Krubitzer and Kaas, 1990; Rockland and Knutson, 2000). Furthermore, the peripheral visual field of the early visual areas is the target of projections from STP and auditory areas (Falchier et al., 2002; Rockland and Ojima, 2003).

Previous investigations using both retrograde tracer injections in V1 (Rockland and Van Hoesen, 1994) and anterograde tracer injections in area TEO (Distler et al., 1993; Rockland et al., 1994) documented projections to area V1 from TEO, but not to calcarine V1. Lack of projections from TEO to areas V1 or V2 in the $\mathrm{CF}$ would be consistent with the predominance of central visual representation in TEO (Boussaoud et al., 1991).

Inferior parietal lobule convexity areas have in common the functional property of generating motor representations integrating sensory and motor inputs. These representations can be used for organizing actions in space or they can remain at the level of 
A
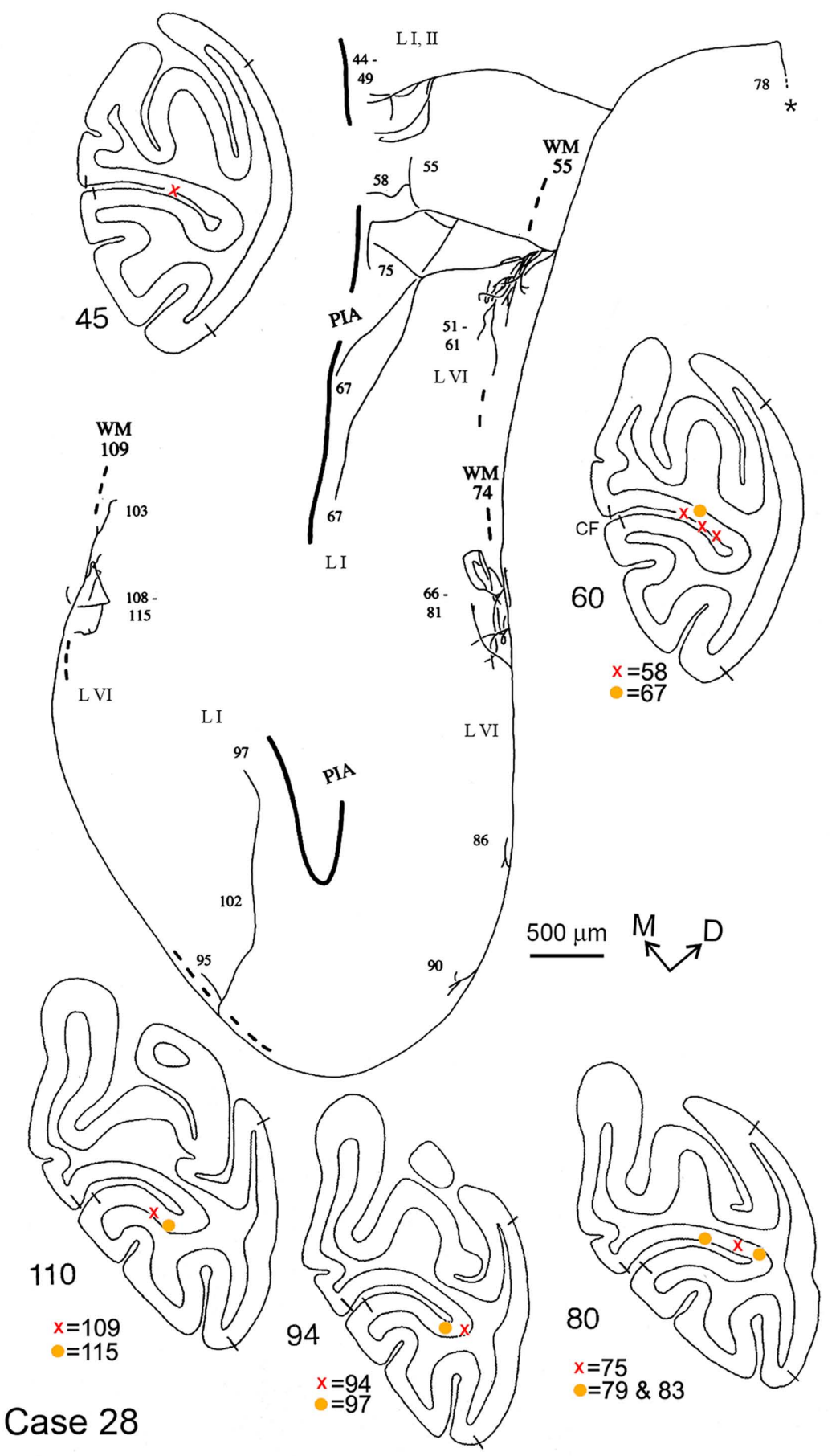

$51-\}_{61}^{11}$

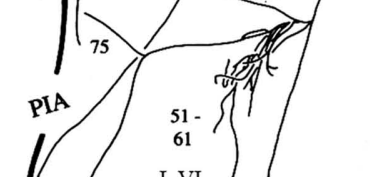

FIGURE 5 | Continued

pure representation subserving the understanding of space relations and actions of others in a subject-centered perspective (Rozzi et al., 2008). Action planning in the parietal cortex may influence perception in the visual periphery with a broad effect on a relatively large visual field representation. It may have a role in modulating peripheral visual stimuli in relation to the planned action, or in the context of top-down shifting spatial attention (see, e.g., Andersen and Buneo, 2002; Berman and Colby, 2009; in humans Rushworth et al., 2001; for attentional processes in V1 see, e.g., Silver et al., 2007; Roelfsema et al., 2010).

Multisensory effects have been discussed in the context of sensory integration and, in particular, shown to be associated with 


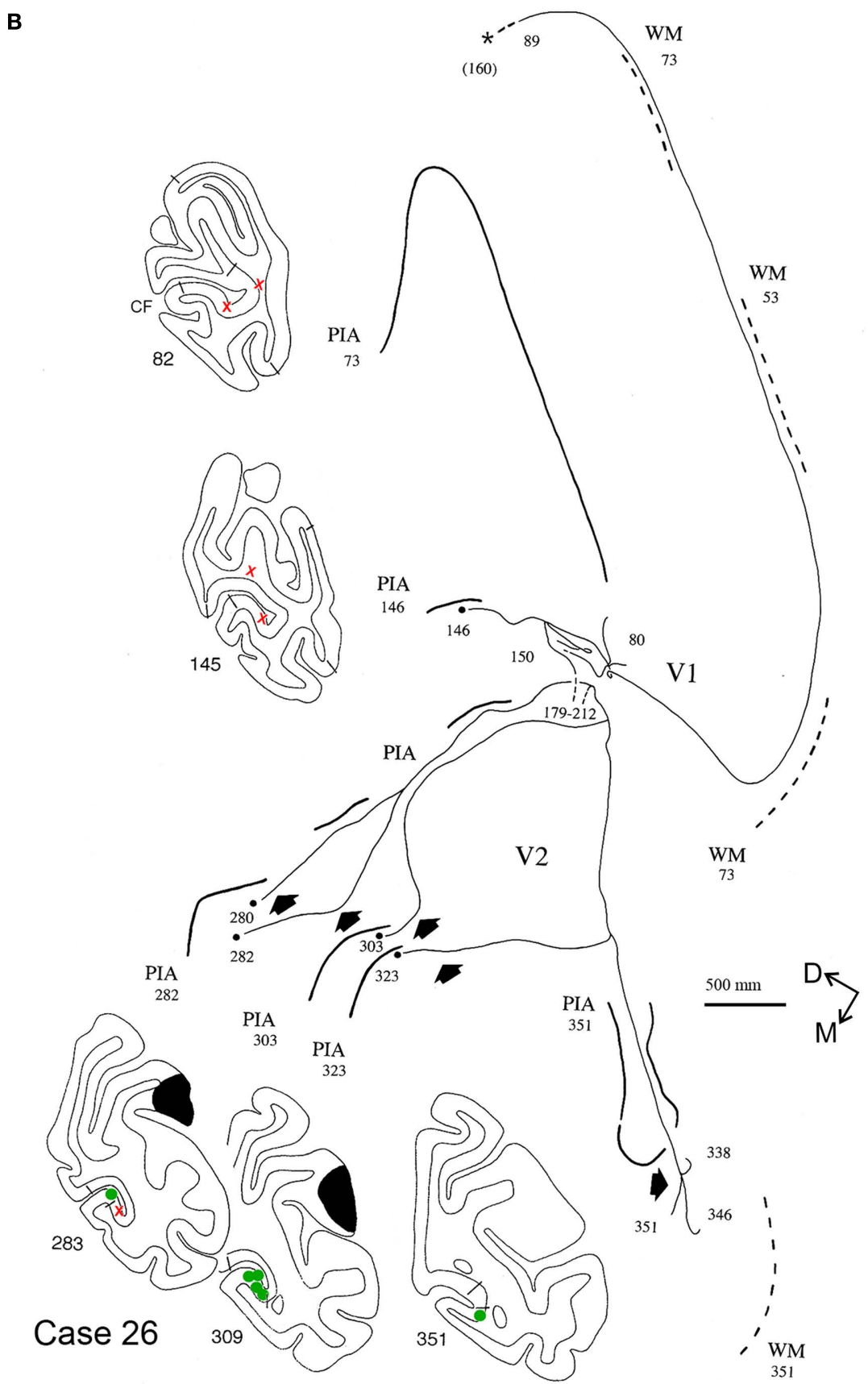

FIGURE 5 | Camera lucida reconstructions of two axons terminating in the $C F$, anterogradely labeled by injections of BDA in parietal areas PF/PFG, Case 28 (A) and PG/Opt, Case 26 (B). Both these axons are widely divergent. The axon in (A) extends over a territory $11.0 \mathrm{~mm}$ DV by $3.5 \mathrm{~mm}$ AP. Terminations are limited to V1, but occur in both supra- and infragranular layers. Four main foci can be discerned, separated by variable intervals of about $0.3-3.0 \mathrm{~mm}$. The axon in (B) has a small terminal focus in layer I of V1 (around section 80), but has terminations mainly in layer I of V2. In V2, four collaterals (short, solid arrows), spaced about $1.0 \mathrm{~mm}$ apart (AP), extend variable distances from the ventral V1/N2 border. The total extent of this axon is $13.0 \mathrm{~mm}$ AP by $3.6 \mathrm{~mm}$ DV. Dashes at sections 179-212 indicate a gap (in the summary reconstruction, but not in the raw data), where a portion of the axon has not been depicted, for the sake of space. Asterisk denotes the main axon, which was followed toward the injection site until section 160 (almost $4 \mathrm{~mm}$ rostral). Conventions as in Figures 2 and 4 reductions in reaction time speed (Wang et al., 2008; Sperdin et al., 2009). In addition, somatosensory inputs to area A1 appear to function as a phase reset of ongoing neuronal oscillations, with the result that accompanying auditory inputs arrive during a phase of high excitability, with amplified neuronal effects (Lakatos et al., 2007). There are similar findings for visual to auditory inputs (Kayser et al., 2008). Recordings of multi-unit activity and single unit responses in the caudal auditory belt, concurrent with 
audio-visual movies, result in a depression of auditory responses by visual stimulation (Kayser and Logothetis, 2007).

\section{CONCLUSION}

Areas V1 and V2 in the CF receive a wide network of nonextrastriate connections, both from modality related auditory and somatosensory areas, and from higher order association cortices. These may be implicated, directly and/or indirectly, in multiply interconnected neural networks.

The projections demonstrated in this report are not dense, especially those to area V1. However, there are precedents where numerically few cells are known to exert a distinct influence; for

\section{REFERENCES}

Andersen, R. A., and Buneo, C. A. (2002). Intentional maps in posterior parietal cortex. Annu. Rev. Neurosci. 25, 189-220.

Baizer, J. S., Ungerleider, L. G., and Desimone, R. (1991). Organization of visual inputs to the inferior temporal and posterior parietal cortex in macaques. J. Neurosci. 11, 168-190.

Banks, M. I., Uhlrich, D. J., Smith, P. H., Krause, B. M., and Manning, K. A. (2011). Descending projections from extrastriate visual cortex modulate responses of cells in primary auditory cortex. Cereb. Cortex. doi: 10.1093/cercor/bhr048. [Epub ahead of print].

Barbas, H. (1988). Anatomic organization of basoventral and mediodorsal visual recipient prefrontal regions in the rhesus monkey. J. Comp. Neurol. 276, 313-342.

Battaglia-Mayer, A., Mascaro, M., and Caminiti, R. (2007). Temporal evolution and strength of neural activity in parietal cortex during eye and hand movements. Cereb. Cortex 17, 1350-1363.

Berman, R., and Colby, C. (2009). Attention and active vision. Vision Res. 49, 1233-1248.

Bizley, J. K., Nodal, F. R., Bajo, V. M., Nelken, I., and King, A. J. (2007). Physiological and anatomical evidence for multisensory interactions in auditory cortex. Cereb. Cortex 17, 2172-2189.

Boussaoud, D., Desimone, R., and Ungerleider, L. G. (1991). Visual topography of area TEO in the macaque. J. Comp. Neurol. 306, 554-575.

Breveglieri, R., Galletti, C., Monaco, S., and Fattori, P. (2008). Visual, somatosensory, and bimodal activities in the macaque parietal area PEc. Cereb. Cortex 18, 806-816.

Bruce, C., Desimone, R., and Gross, C. G. (1981). Visual properties of neurons in a polysensory area in superior temporal sulcus of the macaque. J. Neurophysiol. 46, 369-384.

Budinger, E., Heil, P., Hess, A., and Scheich, H. (2006). Multisensory processing via early cortical stages: connections of the primary auditory cortical field with other sensory systems. Neuroscience 143, 1065-1083.

Campi, K. L., Bales, K. L., Grunewald, R., and Krubitzer, L. (2010). Connections of auditory and visual cortex in the prairie vole (Microtus ochrogaster): evidence for multisensory processing in primary sensory areas. Cereb. Cortex 20, 89-108.

Cavada, C., and Goldman-Rakic, P. S. (1989). Posterior parietal cortex in rhesus monkey: II. Evidence for segregated corticocortical networks linking sensory and limbic areas with the frontal lobe. J. Comp. Neurol. 287, 422-445.

Christman, S. D., and Niebauer, C. L. (1997). "The relation between leftright and upper-lower visual field differences," in Cerebral Asymmetries in Sensory and Perceptual Processing, ed. S. Christman (Amsterdam: Elsevier), 263-296.

Clavagnier, S., Falchier, A., and Kennedy, H. (2004). Long-distance feedback projections to area V1: implications for multisensory integration, spatial awareness, and visual consciousness. Cogn. Affect. Behav. Neurosci. 4, 117-126.

Ding, S. L., Van Hoesen, G., and Rockland, K. S. (2000). Inferior parietal lobule projections to the presubiculum and neighboring ventromedial temporal cortical areas. J. Comp. Neurol. 425, 510-530.

Distler, C., Boussaoud, D., Desimone, R., and Ungerleider, L. G. (1993). Cortical connections of inferior temporal area TEO in macaque monkeys. J. Comp. Neurol. 334, 125-150.

example, the sparse population of cholinergic interneurons in the nucleus accumbens (Witten et al., 2010). The projections to V1 might also be potentiated by the recurrent network of direct and indirect connections; that is, sparse direct projections to V1 may be reinforced via projections to $\mathrm{V} 2$ or other areas, projecting in turn to V1 or V2 or both.

\section{ACKNOWLEDGMENTS}

We would like to thank H. Mashiko, Y. Abe, and D. Potapov for expert histological assistance; and Tina Knutson and Jon Andresen for contributing to the axon reconstructions. This work was supported by research funds from RIKEN Brain Science Institute.

Doty, R. W. (1983). Nongeniculate afferents to striate cortex in macaques. $J$. Comp. Neurol. 218, 159-173.

Falchier, A., Clavagnier, S., Barone, P., and Kennedy, H. (2002). Anatomical evidence of multimodal integration in primate striate cortex. J. Neurosci. 22, 5749-5759.

Falchier, A., Schroeder, C. E., Hackett, T. A., Lakatos, P., NascimentoSilva, S., Ulbert, I., Karmos, G., and Smiley, J. F. (2010). Projection from visual areas V2 and prostriata to caudal auditory cortex in the monkey. Cereb. Cortex 20, 1529-1538.

Fogassi, L., and Luppino, G. (2005). Motor functions of the parietal lobe. Curr. Opin. Neurobiol. 15, 626-631.

Foxe, J. J., Wylie, G. R., Martinez, A., Schroeder, C. E., Javitt, D. C., Guilfoyle, D., Ritter, W., and Murray, M. M. (2002). Auditory-somatosensory multisensory processing in auditory association cortex: an fMRI study. J. Neurophysiol. 88, 540-543.

Gattass, R., Gross, C. G., and Sandell, J. H. (1981). Visual topography of V2 in the macaque. J. Comp. Neurol.201, 519-539.

Ghazanfar, A. A., Maier, J. X., Hoffman, K. L., and Logothetis, N. K. (2005). Multisensory integration of dynamic faces and voices in rhesus monkey auditory cortex. J. Neurosci. 25, 5004-5012.

Gregoriou, G. G., Borra, E., Matelli, M., and Luppino, G. (2006). Architectonic organization of the inferior parietal convexity of the macaque monkey. J. Comp. Neurol. 496, 422-451.

Horton, J. C., Hocking, D. R., and Adams, D. L. (1999). Metabolic mapping of suppression scotomas in striate cortex of macaques with experimental strabismus. J. $\mathrm{Neu}$ rosci. 19, 7111-7129.

Kayser, C., and Logothetis, N. K. (2007). Do early sensory cortices integrate cross-modal information? Brain Struct. Funct. 212, 121-132.
Kayser, C., Petkov, C. I., and Logothetis, N. K. (2008). Visual modulation of neurons in auditory cortex. Cereb. Cortex 18, 1560-1574.

Kennedy, H., and Bullier, J. (1985). A double-labeling investigation of the afferent connectivity to cortical areas $\mathrm{V} 1$ and $\mathrm{V} 2$ of the macaque monkey. J. Neurosci. 5, 2815-2830.

Krubitzer, L. A., and Kaas, J. H. (1990). Cortical connections of MT in four species of primates: areal, modular, and retinotopic patterns. Vis. Neurosci. 5, 165-204.

Lakatos, P., Chen, C. M., O'Connell, M. N., Mills, A., and Schroeder, C. E. (2007). Neuronal oscillations and multisensory interaction in primary auditory cortex. Neuron 53, 279-292.

Lewis, J. W., and Van Essen, D. C. (2000). Mapping of architectonic subdivisions in the macaque monkey, with emphasis on parieto-occipital cortex. J. Comp. Neurol. 428, 79-111.

Lomber, S. G., Meredith, M. A., and Kral, A. (2010). Cross-modal plasticity in specific auditory cortices underlies visual compensations in the deaf. Nat. Neurosci. 13, 1421-1427.

Lyon, D. C., and Kaas, J. H. (2002). Evidence from V1 connections for both dorsal and ventral subdivisions of $\mathrm{V} 3$ in three species of New World monkeys. J. Comp. Neurol. 449, 281-297.

Maunsell, J. H., and Van Essen, D. C. (1983). The connections of the middle temporal visual area (MT) and their relationship to a cortical hierarchy in the macaque monkey. $J$. Neurosci. 3, 2563-2586.

Merabet, L. B., Hamilton, R., Schlaug, G., Swisher, J. D., Kiriakopoulos, E. T., Pitskel, N. B., Kauffman, T., and Pascual-Leone, A. (2008). Rapid and reversible recruitment of early visual cortex for touch. PLoS ONE 3, e3046. doi: 10.1371/journal.pone.0003046

Molholm, S., and Foxe, J. J. (2010). Making sense of multisensory integration. Eur. J. Neurosci. 31, 1709-1712. 
Palmer, S. M., and Rosa, M. G. (2006). A distinct anatomical network of cortical areas for analysis of motion in far peripheral vision. Eur. J. Neurosci. 24, 2389-2405

Pandya, D. N., and Seltzer, B. (1982). Intrinsic connections and architectonics of posterior parietal cortex in the rhesus monkey. J. Comp. Neurol. 204, 196-210.

Previc, F. C. (1990). Functional specialization in the lower and upper visual fields in humans: its ecological origins and neurophysiological implications. Behav. Brain Science 13, 519-575.

Rockland, K. S. (2002). Non-uniformity of extrinsic connections and columnar organization. J. Neurocytol. 31, 247-253.

Rockland, K. S., and Drash, G. W. (1996). Collateralized divergent feedback connections that target multiple cortical areas. J. Comp. Neurol. 373, 529-548.

Rockland, K. S., and Knutson, T. (2000). Feedback connections from area MT of the squirrel monkey to areas V1 and V2. J. Comp. Neurol. 425, 345-368.

Rockland, K. S., and Ojima, H. (2003). Multisensory convergence in calcarine visual areas in macaque monkey. Int. J. Psychophysiol. 50, 19-26.

Rockland, K. S., Saleem, K. S., and Tanaka, K. (1994). Divergent feedback connections from areas V4 and TEO in the macaque. Vis. $\mathrm{Neu}$ rosci. 11, 579-600.

Rockland, K. S., and Van Hoesen, G. W. (1994). Direct temporal-occipital feedback connections to striate cortex (V1) in the macaque monkey. Cereb. Cortex 4, 300-313.

Rockland, K. S., and Van Hoesen, G. W. (1999). Some temporal and parietal cortical connections converge in
CA1 of the primate hippocampus. Cereb. Cortex 9, 232-237.

Roelfsema, P. R., van Ooyen, A., and Watanabe, T. (2010). Perceptual learning rules based on reinforcers and attention. Trends Cogn. Sci. 14, 64-71.

Rokni, D., Llinas, R., and Yarom, Y. (2008). The morpho/functional discrepancy in the cerebellar cortex: looks alone are deceptive. Front. Neurosci. 2:2. doi: 10.3389/neuro.01.036.2008

Rozzi, S., Ferrari, P. F., Bonini, L., Rizzolatti, G., and Fogassi, L. (2008). Functional organization of inferior parietal lobule convexity in the macaque monkey: electrophysiological characterization of motor, sensory and mirror responses and their correlation with cytoarchitectonic areas. Eur. J. Neurosci. 28, 1569-1588.

Rushworth, M. F., Ellison, A., and Walsh, V. (2001). Complementary localization and lateralization of orienting and motor attention. Nat. Neurosci. 4, 656-661.

Schall, J. D., Morel, A., King, D. J., and Bullier, J. (1995). Topography of visual cortex connections with frontal eye field in macaque: convergence and segregation of processing streams. J. Neurosci. 15, 4464-4487.

Shams, L., and Kim, R. (2010). Crossmodal influences on visual perception. Phys. Life Rev. 7, 269-284.

Shipp, S., and Zeki, S. (1989). The organization of connections between Areas V5 and V1 in macaque monkey visual cortex. Eur. J. Neurosci. 1, 309-332.

Silver, M. A., Ress, D., and Heeger, D. J. (2007). Neural correlates of sustained spatial attention in human early visual cortex. J. Neurophysiol. 97, 229-237.
Smith, P. H., Manning, K. A., and Uhlrich, D. J. (2010). Evaluation of inputs to rat primary auditory cortex from the suprageniculate nucleus and extrastriate visual cortex. J. Comp. Neurol. 518, 3679-3700.

Sperdin, H. F., Cappe, C., Foxe, J. J., and Murray, M. M. (2009). Early, lowlevel auditory-somatosensory multisensory interactions impact reaction time speed. Front. Integr. Neurosci. 3:2. doi: 10.3389/neuro.07.002.2009

Stanton, G. B., Bruce, C. J., and Goldberg, M. E. (1995). Topography of projections to posterior cortical areas from the macaque frontal eye fields. J. Comp. Neurol. 353, 291-305.

Ungerleider, L. G., and Desimone, R. (1986). Projections to the superior temporal sulcus from the central and peripheral field representations of V1 and V2. J. Comp. Neurol. 248, 147-163.

Van Essen, D. C., Newsome, W. T., and Maunsell, J. H. (1984). The visual field representation in striate cortex of the macaque monkey: asymmetries, anisotropies, and individual variability. Vision Res. 24, 429-448.

Vercelli, A., Repici, M., Garbossa, D., and Grimaldi, A. (2000). Recent techniques for tracing pathways in the central nervous system of developing and adult mammals. Brain Res. Bull. 51, 11-28.

Von Bonin, G., and Bailey, P. (1947). The neocortex of Macaca mulatta. Urbana, IL: University of Illinois Press.

Wang, Y., Celebrini, S., Trotter, Y., and Barone, P. (2008). Visuoauditory interactions in the primary visual cortex of the behaving monkey: electrophysiological evidence. BMC Neurosci. 9, 79-94. doi: 10.1186/1471-2202-9-79
Witten, I. B., Lin, S. C., Brodsky, M., Prakash, R., Diester, I., Anikeeva, P., Gradinaru, V., Ramakrishnan, C., and Deisseroth, K. (2010). Cholinergic interneurons control local circuit activity and cocaine conditioning. Science 330, 1677-1681.

Zhong, Y. M., and Rockland, K. S. (2003). Inferior parietal lobule projections to anterior inferotemporal cortex (area TE) in macaque monkey. Cereb. Cortex 13, 527-540.

Zhong, Y. M., Yukie, M., and Rockland, K. S. (2006). Distinctive omorphology of hippocampal CA1 terminations in orbital and medial frontal cortex in macaque monkeys. Exp. Brain Res. 169, 549-553.

Conflict of Interest Statement: The authors declare that the research was conducted in the absence of any commercial or financial relationships that could be construed as a potential conflict of interest.

Received: 11 February 2011; paper pending published: 01 April 2011; accepted: 06 June 2011; published online: 22 June 2011.

Citation: Borra E and Rockland KS (2011) Projections to early visual areas $V 1$ and $V 2$ in the calcarine fissure from parietal association areas in the macaque. Front. Neuroanat. 5:35. doi: 10.3389/fnana.2011.00035

Copyright (c) 2011 Borra and Rockland.

This is an open-access article subject to a non-exclusive license between the authors and Frontiers Media SA, which permits use, distribution and reproduction in other forums, provided the original authors and source are credited and other Frontiers conditions are complied with. 